हो

-

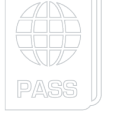

\title{
POSSIBILITIES OF SUSTAINABLE AIRPORT BUSINESS
}

\author{
Marija Stojanović*, \\ Nikica Radović, \\ Angelina Njeguš
}

Singidunum University, Belgrade, Serbia

\begin{abstract}
:
Raising awareness of the negative impact of air traffic on climate changes with the greenhouse effect is increasing, so airports are also expected to contribute to reducing its impact on the environment. The airport area has the greatest negative impact not only because of harmful exhaust gases, aircraft noise, but also because of seizure of green areas, fragmentation of natural wildlife habitats, depletion of non-renewable natural resources, energy consumption, generation of waste left behind by tourists, soil and water pollution which are just some of the negative effects that air traffic has on the environment. Negative impacts on the environment extend to the land outside the airport, which can further affect the efficiency of the airport, and thus the sustainable development of the airport. Air travel has made it easier for tourists to get to the other side of the world faster, and the LCC has made transportation accessible to a large number of people. The increased number of tourist arrivals has its positive and negative impact on the population, which is reflected in the quality of life and health of people living near the airport. Reducing the negative impact of air traffic on the environment should be the main goal of airport management. The paper analyzes the sustainable development of the airport with reference to Constantine the Great Airport in Nis, as well as several good examples of airport practice in the world.
\end{abstract}

\section{Keywords:}

sustainable airport development, airport sustainability, sustainable air traffic, Constantine the Great Airport

\section{INTRODUCTION}

The increase in the living standard of the population resulted in a greater possibility, desire and need to travel, and therefore to an increase in the air traffic intensity. Air transport has many advantages compared to the other forms of transport: faster and better quality of transport, covering long distances, safer transport, etc., and according to the UNWTO, $58 \%$ of tourist movements in 2018 were realized through air transport (UNWTO, 2019). In order to contribute to the reduction of the negative impact of air traffic on the environment (pollution as well as aircraft noise), operational procedures which air carriers should implement during the take-off and landing have been established (for ex. the Chicago Convention or Directive 2002/49 EC of the European Parliament and the Council on the assessment and management of environmental noise).
Correspondence: Marija Stojanović

e-mail:

marija.stojanovic.17@singimail.rs 
The local population living near the airport has several health issues due to the aircraft noise: they suffer from sleep disorders, stress, and hypertension, have difficulty working as well as concentrating.

In accordance with the principles of sustainable tourism at the destination, there must be cooperation of all the actors in order to meet the needs and expectations of tourists and achieve certain economic effects by connecting foreign investors interested in investing in the region of the airport service area. In addition, it should enable the inclusion of the local population in providing services to tourists which would be beneficial for the local community, and which in turn would protect and improve the local environment thus enabling the preservation of cultural heritage.

Nis, as an international tourist center with Nis Spa, along with the mountain centers Kopaonik and Stara Planina, as well as Sokobanja which gravitate towards it, enables the development of health tourism, rural tourism, cultural tourism, winter sports and congress tourism in this part of Serbia. Having in mind the increasing global need for air traffic as well as its influence on the development of tourism in Serbia, the offer of airlines at Constantine the Great Airport in Nis has been expanded in order to attract more tourists.

The benefits that Constantine the Great Airport brings to the city of Nis and its surrounding area are not only reflected in the positive effects and the satisfaction of people who live there, but also in the increased number of foreign visitors, higher accommodation occupancy rate, larger number of employees, increased investments of foreign companies in the southern Serbia industrial development, infrastructure development and better connections with other cities in the region, the organization of numerous festivals, cultural events and tourist attractions in Nis which are becoming more accessible to foreign tourists. Gastronomy and wineries contribute to positive image that foreign travelers get about this part of Serbia. In addition, the proximity of the airport to the mountains and spas is an advantage that should be used for further development.

\section{SYNERGY OF SUSTAINABLE TOURISM AND AIR TRANSPORT}

Although air traffic, as a basic means of mobility in the global society, has a positive effect on the development of tourism, traffic, economy and quality of social life, it also has negative impacts on the environment and people, especially those living near the airport. Ensuring the development of sustainable transport occupies a very important place in the EU Sustainable Development Strategy and is essential for the society and economy. Sustainability is becoming synonymous with "growth permits".

Sustainability at small airports cannot only be seen as "green" but must also have a holistic approach to sustainability that enables EONS: (ACRP Synthesis 69, 2016)

\section{E - Economic viability}

$\mathrm{O}$ - Operation efficiency

$\mathrm{N}$ - Natural resource conservation - ecological sustainability, air quality improvement, water quality preservation and conservation, climate change, conservation of energy / renewable sources of energy, noise reduction, waste management, recycling, land and property use

S - Social responsibility

Figure 1. Holistic approach to sustainability at small airports - EONS

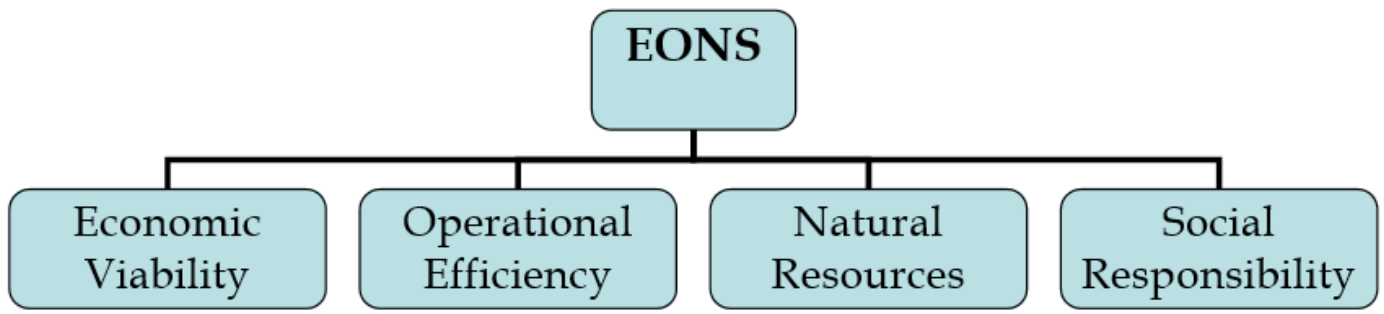


IATA (International Air Transport Association) members are persistently committed to reducing greenhouse gas emissions. One of the main elements in achieving these goals may be the introduction of low-carbon (SAF) Sustainable Aviation Fuels or the introduction of electric aircraft. Achieving these goals requires government support at the national and international levels. What is necessary is the professional education of all participants at the airport, as well as state support to producers in the production of alternative sustainable jet fuel. Constantine the Great Airport could contribute to sustainability if it insists on landing only planes that use biofuel, but the EU has not yet shown sufficient readiness to support the decarbonisation of air traffic which requires raising public awareness about reducing $\mathrm{CO} 2$ emissions. It is recommended to enter the carbon accreditation process and obtain an international certificate which would indicate a business that is in line with the goals of sustainable development. Given that airports with smaller capacities, such as Constantine the Great Airport in Nis, do not have sufficient financial resources to support themselves, as well as to commit themselves to sustainability efforts in accordance with the goals of sustainable development, the FAA (Federal Aviation Administration) has launched the initiative through an airport improvement program, providing support for the development of sustainable master plans and necessary documentation for the sustainability of airports. This would give the airport an advantage in the market which is the basis for future growth, and the airport could promote itself as a socially responsible company (ACRP Synthesis 69, 2016).

Constantine the Great Airport in Niš is located in a zone with very favorable weather conditions, which is an important reason for its use as an alternative airport compared to other airports in the region. With the introduction of numerous LCC (Low Cost Company) lines, it has become attractive to travelers in the wider region as well. According to the Nis Airport data, which show that the tendency of growth of the number of passengers at the airport is constant, there is an increase of 57.8\% in January 2020 when compared to January 2019. The capacity of the airport is three planes per hour and a total of 100,000 service passengers, which indicates the fact that the airport has exceeded its carrying capacity in the last 3 years. In 2019, it served 422,255 passengers with a total of 3934 air operations (www.nis-airport.com/en/traffic-figures/). The solution to the problem of the airport carrying capacity is seen in the construction of a new or expansion of an existing airport facility, which can take into account the use of energy efficient materials and thus reach some of the goals of sustainable development.

Smaller airports, such as "Constantine the Great" in Niš, must generate revenue in ways other than fees for airport services, fees for the use of passenger terminals, fees for parking aircraft, government investment, certain commercial services offered by the airport, renting advertising space inside and outside the airport, selling fuel, renting office space, facilities and land, passenger car parking services, transfer services, etc. Recycling programs can pose an additional income that can generate a financial benefit by selling recyclable materials or using LED lighting and can lead to better economic effects by having cheaper bills for electric energy consumption, and at the same time, they represent a form of participation in achieving sustainability goals (ACRP Synthesis 66, 2015).

Launching and implementing sustainability programs at Constantine the Great Airport can have many benefits: increased business competitiveness, reduced operating costs, efficient and greater use of assets, reduced environmental and noise impact, optimization of new and better technologies, improved working environment for employees - higher labor productivity, a useful tool for engaging stakeholders, creating partnerships, improving passenger satisfaction, attracting business to the airport.

The introduction of sustainability at the airport must go step by step:

- Short-term: awareness building, improving sustainability through technology (awareness training, human resource management and internal communication).

- Medium term: sustainable business - sustainable facilities, efficient energy, security including bio-sensors, robots, data management.

- Long-term: implement a disruption plan (crisis management), use of security platforms, strong international cooperation of the authorities, smart safety equipment, 0 emissions from air traffic, redirection of protective personnel due to the use of robotics, etc. 
We can list several selected cases funded by the FAA as good examples of the introduction of sustainability at small airports in the world (ACRP Synthesis 69, 2016). The main goal of these examples is to show the ideas of the sustainable development initiative implemented at small airports around the world, which can be applied at Constantine the Great Airport. Although small airports have much less resources (financial resources, staff, facilities) compared to large airports, they should be implementing sustainable initiatives. They are more innovative when it comes to the implementation of sustainability, and thus they find cheaper solutions for the implementation of plans for sustainable development. The main application should not be focused on the number or scope of implemented initiatives, but on the necessary transformation of the ways personnel think which would lead them to think in a sustainable way when conducting business operations and making their business decisions.

\section{EXAMPLE 1: Airport in Colorado - web sustainability platform}

The first state to be funded by the Federal Aviation Administration is Colorado. Airports in Colorado have created an Internet web platform for customizing airport sustainability plans. After developing a network tool that enables airport staff to insert distinct parameters and answer various questions, a sustainability plan has been created. Today, it has an online information management system available to all airports in Colorado. The implementation of this segment of sustainable business at Constantine the Great Airport and the development of a web platform would innovate the existing business processes.

\section{EXAMPLE 2: Airport Riverside - California}

This airport sought to reduce electricity consumption so it replaced all lights on the runway, parking lot, taxiways with LED lighting. The power of light has improved, and energy consumption has decreased significantly. Motion sensors are installed in the building which allows them to turn off automatically if the office space is empty. In order to reduce water use by $25 \%$ due to urban drought and participation in austerity measures, Riverside Airport replaced grass and vegetation on $30 \%$ of its surface with gravel and concrete and they replaced urinals with lower water flow in men's toilets by means of which they reduced the amount of water used in rinsing. Based on this example of good practice, with the possibility to implement LED lighting at Constantine the Great Airport, the costs of electricity that surpass the other fixed operating costs would be minimized.

\section{EXAMPLE 3: Airport Lakeland Linder in Florida}

In order to significantly reduce airport utility costs, Lakeland Linder airport has implemented a plan to produce renewable energy by building a solar field on its surface. In cooperation with the city, the airport ceded the city's land and installed over 18000 solar panels on 40 hectares of the airport area. This is the first solar field at the airport of a smaller size that generates over 9 million $\mathrm{kW} / \mathrm{h}$ of solar electricity annually and saves over 250000 US dollars in energy credits per year. As a result, the airport's electricity costs are almost eliminated. By analyzing the possibilities of valorization of sustainable energy sources in the city of Nis, it is estimated that this good example of practice could be implemented in the businesses of Constantine the Great Airport and thus contribute to minimizing business costs and increasing profitability.

\section{SUSTAINABILITY OF AIR TRAFFIC AT AIRPORTS USING GIS}

In line with the goals of sustainable development, there are many benefits of applying GIS in the responsible business and that entails the following: reduced $\mathrm{CO} 2$ emissions, noise reduction and environmental protection, the possibility to monitor variables, make real-time analysis, deliver sustainable growth, share the technology to ensure accurate data use within the organization and share resources necessary for further sustainable development. When using GIS, one can look at the current situation on air quality and determine the future scenario in the processes of expanding the capacity of air traffic. By digitally managing airport intelligence information, airports will operate more efficiently and sustainably (Ağaçsapan and Çabuk, 2019). 
The goal of the airport should be: to provide not only sustainable, safe and ecologically friendly business processes, but also modern and efficient airport infrastructure, high quality service, and to hire a talented and motivated team of employees. The application of modern technology affects the development of tourism and the aviation industry, and consequently its sustainability which is why the application is necessary. Despite large efficiency gains, total carbon emissions will continue to grow with tourism growth, indicating the need for more innovative and progressive business models that enable companies to operate in an ecological and sustainable manner.

By combining BIM technology (Building Information Modeling) and GIS, the system is enriched with many tools, such as takeoff amount, cost estimation, structural safety analysis, four-dimensional workspace where various operations can be done, such as building performance simulation, planning, managing resources and the site. Furthermore, the system also incorporates a tree structure and a 3D graphic system that enable the visualization of temporal, relational, hierarchical, and spatial information. Alongside with the advanced 3D graphics platform and BIM technology, projects regarding future designs related to the sustainable expansion of airport capacity will be developed, and this would be the main goal of introducing the location at the airport (Ponjavic and Karabegovic, 2019). A well-designed space of airport buildings and infrastructure as well as performing complex business processes at the airport provide the opportunity to reduce the negative impact on the environment and indicate a contribution to more sustainable practices. An increasing number of airports as well as owners of other properties associated with airports use BREEAM and CEEQUAL technology to assess the viability of the facility (Leonard and Nicholson, 2020).

\section{CONCLUSION}

The main goal of this research work is to place emphasis on the necessity of sustainable infrastructure in the construction of the airport complex in Nis and its importance for the city, region and even the state. The offer of LCC, which influenced the attraction of an increasing number of foreign tourists, enabled the development of the tourism economy of this part of Serbia and, at the same time, influenced the life of the local community. The idea is to point out the necessity of cooperation between the airport and all partners and state entities for the purpose of planning and implementing environmental protection measures in accordance with the standards and best practices. It is necessary to set sustainability goals at all levels of airport management as well as continuous monitoring and implementation of operational procedures. Air traffic will continue to be the fastest and most comfortable way to travel, especially when it comes to covering long distances. Innovations in the business processes of Constantine the Great Airport, both in terms of information and communication and through the application of renewable energy sources, can greatly improve the business and image of this airport, all with the aim to develop sustainable and responsible tourism. In order for the business to be responsible, our obligation is to minimize damages caused by air traffic, and negative impacts brought by over-tourism every year, so that the development of tourism in this area can progress and coexist with the environment.

\section{REFERENCES}

Ağaçsapan, B. \& Çabuk, A. (2019). Sustainable Aviation: GIS For Airport. GSI Journals Serie B: Advancements in Business and Economics, 2(1).

Kambouroglou, P. (October 2019). The airport's sustainability agenda - contributing positively to a better planet and AVSEC. from http://www.airport-business.com/2019/10/airports-sustainability-agenda-contributingpositively-better-planet-avsec/, Retrieved: January 21, 2020

Nis Constantine the Great Airport. Statistics, from http://nis-airport.com/en/traffic-figures/, Retrieved: February 4,2020

IATA, Developing Sustainable Aviation Fuel (SAF), from https://www.iata.org/en/programs/environment/ sustainable-aviation-fuels/, Retrieved: January 31, 2020

Leonard, D. \& Nicholson, I. (2020). "How to make airports sustainable” International Airport Review, issue 03, Jun 2020, p.43-45 
National Academies of Sciences, Engineering and Medicine (2016). ACRP Synthesis 69, Airport Sustainability Practices Drivers and Outcomes for Small Commercial and General Aviation Airports, Washington, DC: The National Academies Press, https://doi.org/10.17226/23486, p.16-25. Retrieved: January 21, 2020

National Academies of Sciences, Engineering, and Medicine (2015). ACRP Synthesis 66, Lessons Learned from Airport Sustainability Plans. Washington, DC: The National Academies Press. https://doi. org/10.17226/22111, p.18

Ponjavić, M. \& Karabegović, A. (2019). Location Intelligence Systems and Data Integration for Airport Capacities Planning. Computers, 8(1), 13.

Sustainable Aviation Resource Guide, Planning, Implementing and Maintaining a Sustainability Program at Airport. (2010). SAGA Resource Guide, p.56

UNWTO Tourism Highlights (2019). UNWTO, Madrid, https://www.e-unwto.org/doi pdf/10.18111/9789284421152, Retrieved: April 21, 2020

Tourism and the Sustainable Development Goals - Journey to 2030, UNWTO, Madrid, January 2018, https:// www.e-unwto.org/doi/epdf/10.18111/9789284419401, Retrieved: January 21, 2020 